\title{
PAULO FREIRE ESTETA: ARTE, FOTOGRAFIA E CINEMA
}

\section{PAULO FREIRE ESTHETE: ART, PHOTOGRAPHY AND CINEMA}

\author{
BERINO, Aristóteles ${ }^{1}$
}

\section{RESUMO}

Paulo Freire é comumente lembrado pela dimensão sobretudo política do seu pensamento pedagógico. No entanto, de forma recorrente e também significativa, pensou a educação como uma realização estética e o professor mesmo como um artista. Neste artigo foram destacadas quatro passagens da obra de Paulo Freire para discutir os sentidos estéticos que atribuiu à educação, além de observar a importância dessa discussão para a teoria e prática da educação popular hoje.

PalaVRas-ChaVe: Paulo Freire; Estética; Arte: Criação; Educação.

\begin{abstract}
Paulo Freire is commonly remembered mainly by the political dimension of his pedagogical thinking. However, in a recurring and also significant way he thought education as an aesthetic achievement and the teacher as an artist. In this article, four passages of Paulo Freire's work were highlighted in order to discuss the aesthetic senses he attributed to education, as well as to observe the importance of this debate for the theory and practice of popular education today.
\end{abstract}

KeY WORDS: Paulo Freire; Aesthetic; Art; Creation; Education

Diz-se que esteta é a "pessoa que põe os valores estéticos acima de todos os outros $^{\prime 2}$. Se não se pode afirmar que Paulo Freire foi um esteta em termos absolutos, no entanto, é possível dizer, sem vacilar, que a estética foi uma questão que sempre esteve presente nos seus escritos e nas suas conversas sobre a educação. $\mathrm{O}$ que gostaria, neste artigo, de modo introdutório ao tema, é discutir os sentidos que a estética adquire em seu pensamento e em sua prática educativa. Vou destacar especialmente quatro passagens encontradas em sua obra para expor a questão, com a observação de que são, no meu entender, suficientemente indicativas do valor que atribuiu à estética.

1 Doutor em Educação (UFF). Professor Associado II do Departamento de Educação e Sociedade do Instituto Multidisciplinar da UFRRJ/Campus Nova Iguaçu e do Programa de Pós-Graduação em Educação, Contextos Contemporâneos e Demandas Populares - PPGEduc/UFRRJ.

2 Cf Dicionário Barsa da Língua Portuguesa. São Paulo: Barsa Planeta, 2005. 2v. 
Não é difícil, como acabei de afirmar, encontrar em Paulo Freire referências à estética. Em seu Pedagogia da autonomia, de 1996, último livro que Paulo Freire publicou antes da sua partida, um breve manual sobre "os saberes necessários à prática educativa" - subtítulo do livro, "ética e estética" constituem uma dessas condições necessárias. Diz ali Freire (2015, p. 34): "A necessária promoção da ingenuidade à criticidade não pode ou não deve ser feita à distância de uma rigorosa formação ética ao lado sempre da estética. Decência e boniteza de mãos dadas". Também na mesma obra, encontramos: "Ensinar e aprender não podem dar-se fora da procura, fora da boniteza e da alegria" (FREIRE, 2015, p. 139). Antes, em 1987, em uma conversa com o educador norte-americano Ira Shor, disse Paulo Freire: "Para mim, conhecer é alguma coisa bonita" (FREIRE, SHOR, 1996, p. 509). Recuando um pouco mais, em 1978, em uma entrevista para o jornal espanhol El País, Paulo Freire (2017, on-line) afirmou: "El educador es un político y un artista". E algumas outras referências poderiam ser aqui lembradas (BERINO, 2017, on-line). 0 fato é que de forma pontilhada ao longo de sua obra, às vezes detendo-se um pouco mais e outras en passant, Paulo Freire referiu-se à educação como estética e o próprio educador como um artista.

Curiosamente, no entanto, enquanto a dimensão política afirmada por Paulo Freire na educação é recorrentemente observada por seus leitores e "denunciada" ${ }^{3}$ por seus detratares, raramente seu par, a estética, é lembrada - como se fosse mais uma contraface e não exatamente pertencentes a uma natureza comum da sua leitura de mundo, tal como ele mesmo expôs. Um dos motivos desse distanciamento pode ser creditado ao Paulo Freire também, já que nem sempre tornou a abordagem sobre estética tão frontal na sua obra. Ou seja, apesar de afirmar sua relevância ao lado da política, fez isso de forma mais esparsa sem uma dedicação teórica tão sistemática. Creio que isso aconteceu também porque sempre foi mais solicitado no sentido de expor sobre os condicionamentos políticos da educação do que discutir outros domínios. E mais, uma forte tradição crítica do pensamento educacional que também não reserva à estética um lugar tão central e decisivo nos debates, pouco contribui para recuperar o assunto no interior da obra de Paulo Freire.

Mas agora, no entanto, vinte anos após a sua partida, ocorrida em 1997, o conhecimento da sua extensa obra, as inúmeras vezes em que a questão da estética de algum modo nela aparece e a consideração de que se trata de um tema também relevante diante de toda a problemática cultural e social que nos deparamos na modernidade tardia, seria um desperdício ignorar sua contribuição para o assunto no campo da educação. Está aí, na atualidade do tema, o interesse e a justificativa para discutir a figuração da estética no pensamento de Paulo Freire.

As quatro referidas passagens da obra de Paulo Freire que vou destacar para a discussão aqui proposta estão: 1) no encontro, já mencionado, com o educador norte-americano Ira Shor; 2) no livro Educação como prática da liberdade; 3) no livro

3 Ver, por exemplo, o movimento Escola Sem Partido. 
e-Mosaicos - Revista Multidisciplinar de Ensino, Pesquisa, Extensão e Cultura do Instituto de Aplicação Fernando Rodrigues da Silveira (CAp-UERJ)

V. 6 - N. 13 - DEZEMBRO 2017 - ISSN: 2316-9303

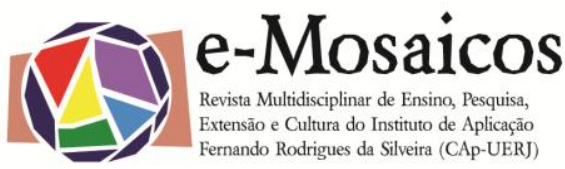

DOI: $10.12957 /$ e-mosaicos.2017.30478

Pedagogia da esperança; 4) no primeiro volume da obra Aprendendo com a própria história, uma conversa com outro educador, Sérgio Guimarães.

No livro Paulo Freire: Uma biobibliografia, uma publicação coordenada por Moacir Gadotti, há um pequeno fragmento de uma conversa entre Paulo Freire e Ira Shor (SHOR; FREIRE, 1996, p. 509), em 1987, originalmente publicada na íntegra em inglês (SHOR; FREIRE, 1987). "O professor como artista", texto curto, é verdade, mas que expõe um rico conteúdo sobre a questão da estética para Paulo Freire. Provocado por seu interlocutor a dizer sobre a "relação entre a educação e a arte, sobre o papel da arte no ensino transformador" (SHOR; FREIRE, 1996, p. 509), Paulo Freire nos oferece uma elaboração com preciosas considerações.

A relação entre a arte e a educação, para Paulo Freire, não se trata de uma relação contingente, mas necessária, que precisa ser vista no coração mesmo da sua concepção de educação: "O que faz da educação uma arte é precisamente quando a educação é também um ato de conhecer" (SHOR; FREIRE, 1996, p. 509). A explicação de Paulo Freire consiste em uma consideração sobre o que é conhecer bastante divergente das concepções usuais e de muito valor para os que enxergam na educação uma prática transformadora. Ele diz: "A amplitude do ato de conhecer é desvelar um objeto, o desvelar dá 'vida' ao objeto" (SHOR; FREIRE, 1996, p. 509). O conhecimento, então, não aparece aqui como uma ação reativa a um objeto. Conhecer atua sobre o que se conhece, transforma, "dá vida". Entre os sentidos figurado e literal da palavra, vida representa um trânsito para o objeto, que deverá sofrer uma alteração no seu estado. Para Paulo Freire, conhecer não é um ato passivo, mas ativo. Conhecer é atuante sobre o que se conhece, portanto. Continua Paulo Freire: "Esta é uma tarefa artística porque nosso conhecimento tem uma dada qualidade de vida, cria e anima objetos com o nosso estudo a respeito deles" (SHOR; FREIRE, 1996, p. 509). Então, conhecimento e criação convergem para uma experiência comum, propriamente artística porque o desvelar de algo, aquilo que estudamos, resulta em algo novo, antes inexistente para quem só após a dedicação do estudo e da pesquisa tem a oportunidade de conhecer, de descobrir. É artístico no sentido da criação.

Observa-se que criação não corresponde a ser meramente apresentado a algum objeto antes ignorado, mas sua apropriação, tornando-o significativo para a própria vida do seu "artista". Só conheço exatamente aquilo que relaciono suas propriedades à minha existência, ou seja, que posso atribuir um sentido à sua presença no mundo. Conhecer é encontrar um lugar no mundo para o objeto do meu interesse de saber. Não o significado previamente determinado, que seria apenas constatado, mas um significado estabelecido pelo indivíduo que se apodera desse objeto. Conhecer o mundo, mais do que lançar um olhar de reconhecimento sobre sua composição já dada, é tecer finalidades absolutamente originais para as criaturas humanas que nele vivem. Conhecer é fazer (re)existir o mundo.

Paulo Freire segue suas considerações dimensionando de modo bastante significativo a correspondência entre estética e educação: "Há muitas coisas que participam da natureza estética do ato de conhecer e de formar. Gestos, entonações 
e-Mosaicos - Revista Multidisciplinar de Ensino, Pesquisa, Extensão e Cultura do Instituto de Aplicação Fernando Rodrigues da Silveira (CAp-UERJ)

V. 6 - N. 13 - DEZEMBRO 2017 - ISSN: 2316-9303

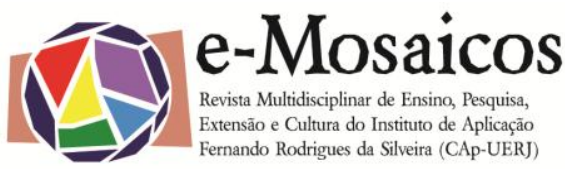

DOI: $10.12957 /$ e-mosaicos.2017.30478

de voz, o caminhar na sala de aula, poses" (SHOR; FREIRE, 1996, p. 509). Aqui Paulo Freire observa a própria corporalidade presente na relação entre educador e educando como lugar também da realização estética que cerca a educação. Na sala de aula ou em outros espaços educativos existem performances que fazem do encontro entre professores e alunos um acontecimento plástico. Educar é atrativo para o olhar e aproximativo entre as pessoas, em uma palavra: sensual. Paulo Freire demonstra uma excitante compreensão sobre a estética como uma experiência inescapável da educação: "Eu penso que no momento em que você entra na sala de aula, no momento que você diz aos estudantes: 'Oi! Como vão vocês?', você inicia uma relação estética". Ou seja, todo o horário de aula é estético. E, na verdade, concluímos obrigatoriamente, a vida nas escolas é integralmente estética.

As produções estéticas nas escolas não se inscrevem de forma absoluta no domínio da consciência, diz Paulo Freire: "Nós podemos fazer todas essas coisas sem estarmos conscientes todo o tempo do seu aspecto estético, do seu impacto sobre a formação dos estudantes através do ensino" (SHOR; FREIRE, 1996, p. 509). Formidável formulação quando pensamos que a aposta da normalização do cotidiano escolar imagina o rígido controle dos seus espaçostempos, enquanto a contrapelo das vigilâncias estudadas, pulsões estéticas são tantas vezes descontroles. Certamente, o inconsciente estético é o verdadeiro tecido das rebeldias e das vitalidades escolares.

Paulo Freire afirma de modo muito enfático o espaço ocupado pela estética em toda educação, sem deixar dúvidas sobre a importância de anotar sua relevância em lugar de reservar um papel secundário ou apenas lateral: "Essas três dimensões estão sempre juntas, há simultâneos momentos de teoria (do conhecimento) e da prática, arte e política, o ato de conhecer é criar e recriar objetos e isto é formar os estudantes que estão conhecendo" (SHOR; FREIRE, 1996, p. 509). Estética, como propriedade do próprio ato de educar, não deveria ser visto como algo que se junta à educação como forma de distração ou de interesse menor. Pelo contrário estética é matéria-prima mesmo do ato de conhecer e educar. No entanto, é claro, as concepções mais conservadoras da educação evitam a criatividade como desafio a mudanças intempestivas, procurando aprisionar 0 artístico da educação em atividades de imaginação contida e baixa intensidade. Mas, para Paulo Freire, o ato de conhecer é desafiador do que existe para transformá-lo, criando e recriando, e até revolucionariamente mudar as pessoas e o mundo.

Embora a realidade estética da educação nem sempre seja vivida de forma consciente, como ressaltou Paulo Freire, ele não deixa de reconhecer a relevância de ter esse conhecimento: "Se o educador se esclarece cada vez mais sobre estas características do ensino, ela ou ele podem desenvolver a eficácia da pedagogia. Conhecendo claramente a natureza necessariamente política e artística da educação, o professor se tornará um político melhor e um artista melhor" (SHOR; FREIRE, 1996, p. 509). Deste modo, saber sobre a presença da estética no ato educativo, tal como ele reafirmou, mais tarde, na Pedagogia da Autonomia, é um saber necessário à prática educativa. Há uma eficácia nesse saber, não no sentido supostamente quantitativo e mensurável do conhecimento, mas na qualidade mesmo dos 


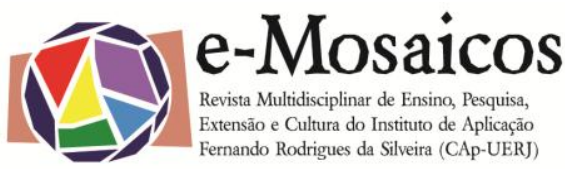

DOI: 10.12957/e-mosaicos.2017.30478

propósitos políticos da educação. Pensando nos desafios hoje da educação pública e popular, é inegável como as infâncias e as juventudes são melhor compreendidas quando vistas singularmente. Trata-se de uma originalidade das classes populares que se realiza, nas escolas, através da artealização e estetização das suas presenças em seu cotidiano (BERINO, 2016). Podemos dizer que a admissão de que a educação é política, mas também artística, mantém os olhos bem abertos para reconhecer as identidades desses personagens. Fechar um dos olhos, como deixar de ver a estética da educação, é produzir invisibilidades. Como consequência, o custo humano é elevado para as classes populares. A política sempre dependeu da estética na educação, sempre foi assim. Contudo, hoje isso é mais notável, está na superfície da vida nas escolas. Para aprender sobre o mundo e nele atuar cultural e socialmente, precisamos estar vivazes, com os nossos alunos, para o político e o estético na educação, sem alienar um do outro.

Para prosseguir com a discussão, vou retornar agora a uma das primeiras obras de Paulo Freire.

Como se sabe, Paulo Freire tornou-se mundialmente conhecido como educador a partir da sua experiência como alfabetizador de adultos, uma atuação especialmente marcante nos anos de 1963 e 1964, quando seu trabalho foi interrompido pelo golpe militar. Prosseguiu com projetos de alfabetização de adultos em outros países. Sua metodologia ficou conhecida como "Método Paulo Freire". O que gostaria de sublinhar é que se tratava de um método em que a atividade plástica exercia uma destacada importância. Embora pudessem ser observados distintos aspectos especialmente visuais e estéticos do "Método Paulo Freire", pretendo lembrar aqui as chamadas "fichas de cultura".

No livro Educação como prática da liberdade, de 1967, Paulo Freire narra a respeito desse trabalho, sobretudo, no âmbito do Movimento de Cultura Popular do Recife. Havia a preocupação de que a alfabetização significasse, "em posição de tomada de consciência", uma "promoção da ingenuidade em criticidade" (FREIRE, 1994, p. 112). Como método, existiam técnicas e dela faziam parte "ajudas visuais", como diz. Com a pretensão de que o alfabetizando adquirisse uma compreensão mais crítica da realidade social, foi concebido como primeiro passo a aquisição do conceito de cultura - a distinção entre natureza e cultura. $O$ sentido de tal aquisição está na capacitação para compreender "o papel ativo do homem em sua e com sua realidade" (FREIRE, 1994, p. 116). A introdução desse conceito de cultura como uma realização comum, de todos os homens, se dá mediante a apresentação de "situações existenciais" através de imagens codificadas, as chamadas "fichas de cultura". Então, os grupos de alfabetizandos são desafiados a compreender as imagens em questão descodificando-as. Nas palavras de Carlos Rodrigues Brandão (1996): "As fichas de cultura são desenhos feitos em cartazes ou projetados em slides. Uma após a outra, elas provocam os primeiros debates, as primeiras trocas de ideias entre o animador e os educandos, ou entre os educandos" (BRANDÃO, 1996, p. 40). 
Notável que o autor da mais conhecida série de imagens dessas fichas de cultura tenha sido o artista plástico Francisco Brennand ${ }^{4}$. Especificamente sobre este material, afirmou Paulo Freire (FREIRE, 1994, p. 117): "Perfeita integração entre educação e arte". Embora o entusiasmo da observação de Paulo Freire contenha a estima pelo artista Francisco Brennand, não se trata de uma integração que existe apenas na presença da arte como criação superlativa, feita tão somente pelo "grande artista". Os desenhos das fichas de cultura são originalmente desenhos sem a pretensão do reconhecimento geralmente destinado à "arte outorgada" (COLI, 1995), mas produções estéticas ordinárias, isto é, próprias da vida comum. Desse modo, o que importa ver aqui é que um dos momentos mais significativos de Paulo Freire como educador, o desenvolvimento do que ficou conhecido como sua criação ou sistematização, o "Método Paulo Freire", é ainda uma criação estética e a sua experimentação também. Cada desenho corresponde a uma situação existencial ali codificada, a uma "redução" que o diálogo entre os participantes de um "círculo de cultura" deverá descodificar para alcançar uma determinada compreensão sobre o que significa. Portanto, no trabalho com as fichas de cultura, o diálogo como uma "pedagogia da comunicação" (FREIRE, 1994, p. 116) é um ato de educação e de fruição estética.

As fichas de cultura vistas como uma criação e não como uma técnica fechada, reproduzida mecanicamente, podem ser recriadas como mídias, utilizando diferentes suportes para as imagens que servem ao jogo desafiador da codificação e descodificação. Reelaborações que acentuam seu caráter de atividade educativa e simultaneamente experimentação estética. A terceira passagem da obra de Paulo Freire, para seguir com a discussão, está presente no livro Pedagogia da esperança, de 1992, e mostra o uso da fotografia como mais uma das práticas estéticas experimentadas com as fichas de culturas. Trata-se de um relato de Paulo Freire que aparece primeiro, em uma versão mais ligeira, na Pedagogia do oprimido (FREIRE, $2005)^{5}$ e é retomado exatamente no livro que tem como subtítulo "Um reencontro com a pedagogia do oprimido", em uma versão um pouco mais alongada.

O ano é 1967. Paulo Freire está em Nova York e faz a sua primeira visita aos Estados Unidos. O episódio foi relatado a ele por uma educadora norte-americana. Reunida com um grupo participante de uma capacitação formado por afroamericanos e porto-riquenhos, ela mostra uma "artística foto", acentua curiosamente Paulo Freire (2011, p. 76), de uma rua com uma grande quantidade de lixo em uma esquina. Ela pergunta ao grupo o que viam na foto. Depois de algum silêncio, alguém responde: "Vemos aí uma rua da América Latina". A educadora observa que

4 No Apêndice do livro Educação como prática da liberdade Paulo Freire inclui desenhos que mostram como eram essas imagens usadas como "situações existenciais" nas fichas de cultura. No entanto, como os originais de Francisco Brennand foram tomados na ocasião do golpe militar de 1964, no livro foram reproduzidos desenhos que foram então solicitados a outro artista, o pintor Vicente de Abreu. Para conhecimento, originas de Francisco Brennand podem ser encontrados agora na internet. Cf <http://forumeja.org.br/node/2499> Acesso em: 17 de setembro de 2017.

${ }^{5}$ Ver p. 179. 


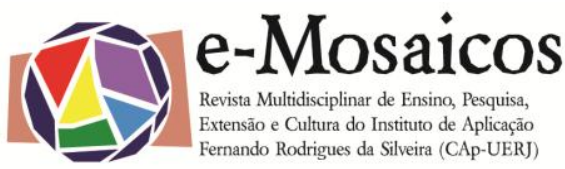

DOI: $10.12957 /$ e-mosaicos.2017.30478

existem anúncios em inglês. Então, alguém diz: "Ou é uma rua da América Latina e nós fomos lá e ensinamos inglês ou pode ser uma rua da África". Mas ela pergunta se não poderia ser uma rua de Nova York, até que alguém responde: "Porque somos os Estados Unidos e não podemos ter isso aí". Finalmente, depois de mais um intervalo de silêncio: "É preciso reconhecer que esta é a nossa rua. Moramos aqui", disse um dos integrantes do grupo. Paulo Freire conta essa história para demonstrar a resistência dos educandos diante do desafio de desvelar a própria realidade. Logo depois, apresenta mais uma narrativa, também envolvendo a fotografia, "outra excelente foto", ele diz (FREIRE, 2011, p. 78). Tratava-se de uma montagem que representava pelo menos seis planos que representavam hierarquicamente condições sociais e econômicas em diferentes áreas de Nova York. A educadora pergunta em qual plano se encontrava o grupo, que também era formado por afro-americanos e porto-riquenhos. A projeção foi supervalorizada, com o grupo se incluindo em um plano não correspondente. Mais uma vez, uma dificuldade de localização identitária diante das imagens, a relutância em se reconhecer às margens de uma cidade fraturada.

Nota-se, com uso de imagens no "Método Paulo Freire", entre codificações e descodificações, uma trama que uma vez vencida faz caminhar a compreensão dos indivíduos que participam dos "círculos de cultura" a propósito de suas existências na geografia social das cidades e na realidade política que os cerca. Claro, não é obrigatório o uso de imagens físicas. No entanto, é parte do "método" e seu uso parece sempre constituir um momento suficientemente exigente e capaz de resultados de superação. As experimentações estéticas, com desenhos, fotografias e outras possibilidades que devem ter ocorrido, proporcionaram para Paulo Freire uma oportunidade educativa entusiasmada pelo artístico. Por isso a exaltação com que sempre se referia à qualidade compreensiva e poética das imagens, sejam desenhos ou fotografias. Paulo Freire fez também uma pedagogia das imagens, é preciso reconhecer. Está presente de forma insofismável em sua obra.

\section{cineasta?}

Depois de encontramos um Paulo Freire fotógrafo, existiria um Paulo Freire

Existem algumas poucas referências cinematográficas na obra de Paulo Freire. Em Pedagogia da esperança, em um longo parágrafo, quando se refere ao caráter crítico da educação popular, observa que mesmo a formação para um ofício é mais ampla que um treinamento estritamente técnico. Então, exemplifica o que está afirmando através da conhecida imagem de um operário na linha de produção de uma fábrica, em um filme: "A classe trabalhadora não deve dela fazer parte simplesmente como o operário de Tempos Modernos se viu às voltas com o ato de apertar parafusos, na produção em série, que Chaplin genialmente criticou".

No segundo volume do livro Aprendendo com a própria história, um dos seus livros de conversas com Sérgio Guimarães, quando Paulo Freire (2000, p. 84) se refere ao contexto de opressão e das lutas dos negros norte-americanos no período em que viveu no país, lembra especialmente de Martin Luther King e também de Malcolm X, observando ainda sobre o último: "Em torno de cuja vida hoje esse outro 
e-Mosaicos - Revista Multidisciplinar de Ensino, Pesquisa, Extensão e Cultura do Instituto de Aplicação Fernando Rodrigues da Silveira (CAp-UERJ)

V. 6 - N. 13 - DEZEMBRO 2017 - ISSN: 2316-9303

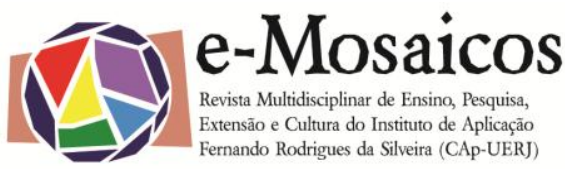

DOI: $10.12957 /$ e-mosaicos.2017.30478

grande negro norte-americano, diretor de cinema, Spike Lee, acaba de fazer um grande filme, para reativar a memória". Refere-se, claro, ao filme Malcolm $X$, de 1992.

São recorrências sobre filmes que provocam a curiosidade de saber se Paulo Freire assistia filmes com algum interesse e quais. Ele refere-se à Malcolm $X$ como um "grande filme", quais outros filmes atribuiria essa distinção?

Pelo menos em Cartas a Cristina, Freire (2003) narra sobre sua frequência infantil ao cinema. Ele diz: "Aplaudia, como grande parte dos meninos de minha geração, a Tom Mix e seu cavalo branco, a Buch Jones e a Rin-TinTin" (FREIRE, 2003, p. 89). Parece que se tratava de uma frequência ansiosa e difícil. Sem passar pela bilheteria, muitas vezes ficava rondando a porta do cinema até que o porteiro liberava sua entrada, quando faltavam apenas dez minutos para encerrar a sessão. Quando a prática foi proibida pelo dono do cinema, remotamente, "somente de tempo em tempo" voltava ao cinema, quando era possível pagar pelo ingresso.

No entanto, a referência mais interessante sobre o cinema em Paulo Freire, que até agora localizei, está no primeiro volume do livro Aprendendo com a própria história. Ali encontramos Paulo Freire simplesmente descrevendo um episódio em que ele diz ter tido a fantasia de filmar! É a quarta e última passagem da sua obra que aqui destaco para a discussão do artigo. Trata-se da recordação do período em que esteve preso pelo regime militar, em 1964. Em uma cela solitária, de $1,70 \mathrm{~m} x$ $0,60 \mathrm{~cm}$, recebe de outro preso, também em uma solitária, pedaços de um frango, através das grades. Então, narra: "'Professor, hoje temos um almoço maravilhoso. Uma amiga me mandou a metade de um frango e vou parti-lo para nós'. E me passou uma parte pelas grades, só víamos nossas mãos no ar, os rostos não. De modo que até hoje me lembro do movimento inquieto da mão dele, um movimento solidário e amoroso" (FREIRE; GUIMARÃES, 1987, p. 60 61). A seguir, completa Paulo Freire: "Enquanto eu comia o meu pedaço de frango me lembrava do momento anterior, dramático e profundamente estético. Mãos que se procuravam no ar para se transferir um pedaço fundamental de vida na perna assada de uma galinha. E pensei que, se fosse cinegrafista, um dia inventaria uma situação dessa só para fazer um close das mãos se procurando" (FREIRE; GUIMARÃES, 1987, p. 61).

Como já vimos, Paulo Freire muitas vezes se referiu à estética como algo inseparável da prática educativa. Para ele, a educação sendo transformadora é também criadora e constitutiva de formas, por isso "estética". Trata-se, antes, da sua própria concepção sobre a existência humana que acompanha seu pensamento sobre a educação. A vida é transformativa e a educação, uma ação da mudança. Portanto, muitas vezes casado com a "ética", a questão da estética nunca foi estranha à sua obra, pelo contrário.

Notável, na passagem citada, é que tivesse a imaginação de traduzir a epifania que viveu em termos cinematográficos, a separação dos corpos pela prisão pôde ser brevemente vencida pelo encontro das mãos, na partilha do alimento. As mãos representam aqui um laço entre indivíduos, apesar da distância que a prisão pretendia impor. A cena narrada foi vista por Paulo Freire como apropriadamente 
e-Mosaicos - Revista Multidisciplinar de Ensino, Pesquisa, Extensão e Cultura do Instituto de Aplicação Fernando Rodrigues da Silveira (CAp-UERJ)

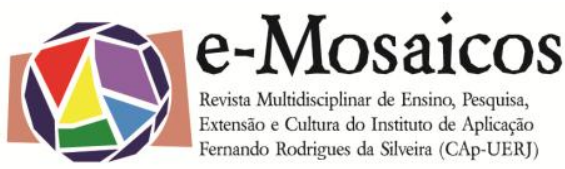

DOI: $10.12957 /$ e-mosaicos.2017.30478

dimensionada através da linguagem do cinema: um close. Trata-se de uma sugestão que poderíamos seguir um pouco mais.

O insight cinematográfico de Paulo Freire nos desafia a pensar que a concepção de mundo, além do que desenvolvemos com própria experiência, não é formada apenas através do contato com outras pessoas e leituras, mas também com imagens. Entre outras expressões visuais, o cinema nos dá formas de ver e compreender a realidade participando das nossas idealizações sociais, das nossas utopias. Assistimos filmes e com a linguagem do cinema também nos expressamos, imaginária, artística e politicamente.

O plano imaginado por Paulo Freire é a proposição de uma imagem que permite focar, diante dos nossos olhos, a dimensão profética e solidária, esperançosa e comum, da sua concepção de mundo. Ao propor uma imagem a partir de um fragmento da sua vivência, codificando valores e conceitos, Paulo Freire termina por reconhecer a cultura visual não apenas como uma prática da comunicação, mas indica também suas possibilidades formativas. O close up freireano é, simultaneamente, pedagogia da imagem e pedagogia política.

A imagem como aproximação pedagógica encontrou no capitalismo tardio uma variedade de artefatos e mídias incomuns na história humana. O cinema é uma dessas fontes. Apesar do raro registro cinematográfico de Paulo Freire na sua obra, a imaginação que Ihe ocorreu, cinquenta anos atrás, contém um significado ainda mais nítido agora. A fugaz intuição cinematográfica de Paulo Freire é também um legado que nos deixou e está disponível para atualização do seu pensamento no século XXI.

São muitos e significativos os momentos da obra de Paulo Freire em que a questão da estética aparece. Entre eles, selecionei quatro passagens para explorar essa presença e indicar que se trata não de uma invasão alienígena na sua concepção de educação, mas de uma existência que a constitui também. Inclusive, através de um depoimento de Ana Mae Barbosa (1996, p. 637) encontramos algumas informações profissionais sobre Paulo Freire que documentam atividades e diálogos em que a arte referida à educação sempre fez parte da sua biografia intelectual. E para que serve saber disso agora, vinte anos depois da sua partida?

A obra de Paulo Freire é uma obra aberta à investigação para atualizações e novas abordagens. O Dicionário Paulo Freire (STRECK; REDIN; ZITKOSKI, 2008) não contém o verbete estética ou arte, apesar da recorrência dessas questões nos escritos de Paulo Freire. Mas tem o verbete boniteza, o que já é indicativo da importância dessa palavra no seu pensamento pedagógico. Estudando a obra de Paulo Freire a partir do nosso tempo, nas primeiras décadas do século XXI, é possível dizer que a pesquisa sobre a questão da estética nos seus escritos, a respeito dos seus sentidos atribuídos à educação, parece relevante, uma necessidade até.

Se pensarmos nos desafios que a educação popular hoje representa, é evidente a constatação de que o diálogo mesmo, sobretudo com as juventudes, é inescapável de uma leitura de mundo em que a estética é admitida como uma 
DOI: 10.12957/e-mosaicos.2017.30478

realidade à flor da pele. As questões mais pregnantes das teorias pós-críticas do currículo (SILVA, 1999) envolvem questões que se presentificam no chão da escola através de comportamentos, performances, gestos, linguagens, gostos e identidades em que as visualidades e estéticas se sobressaem. Apesar da contemporaneidade dessas questões, ainda encontramos em Paulo Freire uma obra para o diálogo com o nosso tempo.

Em uma era em que até o capitalismo é artista (LIPOVETSKY; SERROY, 2015), ou seja, que a acumulação de capital se realiza também através da produção de subjetividades em que a realização estética é um dos seus campos de força, não desfrutar das vezes em que Paulo Freire dedicou-se a pensar a existência como fruição e plástica, é desperdiçar um autor que ainda é relevante para conceber e praticar uma pedagogia da liberdade e do oprimido.

\section{REFERÊNCIAS BIBLIOGRÁFICAS}

BARBOSA, Ana Mae. Paulo Freire e a arte-educação. In: GADOTTI, Moacir (org). Paulo Freire: Uma biobibliografia. São Paulo: Cortez/Instituto Paulo Freire; Brasília: UNESCO, 1996. p. 637-639.

BERINO, Aristóteles. Existência e presença criadora em Paulo Freire. Disponível em: <http://aristotelesberino.blogspot.com.br/2017/04/existencia-e-presenca-criadoraem-paulo.html> Acesso em: 2 de setembro de 2017.

. Juventudes, estetização da escola e artealização do cotidiano: olhar e imagens na pesquisa em educação. Visualidades. Goiânia, v. 14 , n. 1, p. 38-53, 2016.

BRANDÃO, Carlos Rodrigues. O que é método Paulo Freire. São Paulo: Brasiliense, 1996.

COLI, Jorge. O que é arte. São Paulo: Brasiliense, 1995

FREIRE, Paulo. Cartas à Cristina: reflexões sobre minha vida e minha práxis. São Paulo: Ed. UNESP, 2003.

Educação como prática da liberdade. Rio de Janeiro: Paz e Terra, 1994.

. La educación es siempre un quehacer politico: Entrevista. 20 maio 1978.

Madri: El País. Entrevista concedida à Karmentxu Marín. Disponível em <https://elpais.com/diario/1978/05/20/sociedad/264463223_850215.html> Acesso em: 5 de setembro de 2017.

. Pedagogia da esperança: Um reencontro com a pedagogia do oprimido. São

Paulo: Paz e Terra, 2011. 
Pedagogia da autonomia: saberes necessários à prática educativa. Rio de Janeiro: Paz e Terra, 2015.

. Pedagogia do oprimido. Rio de Janeiro: Paz e Terra, 2005.

FREIRE, Paulo; GUIMARÃES, Sérgio. Aprendendo com a própria história: volume I. Rio de Janeiro: Paz e Terra, 1987.

FREIRE, Paulo; GUIMARÃES, Sérgio. Aprendendo com a própria história: volume II. Rio de Janeiro: Paz e Terra, 2000.

LIPOVETSKY, Gilles; SERROY, Jean. $A$ estetização do: viver na era do capitalismo artista. São Paulo: Companhia das Letras, 2015.

SILVA, Tomaz Tadeu da. Documentos de identidade: uma introdução às teorias do currículo. Belo Horizonte: Autêntica, 1999.

SHOR, IRA; FREIRE, PAULO. O professor como artista. In: GADOTTI, Moacir (org). Paulo Freire: Uma biobibliografia. São Paulo: Cortez/Instituto Paulo Freire; Brasília: UNESCO, 1996. p. 509 $11-31,1987$.

. What is the Dialogial Method? Journal of Education. Boston, v. 169, n. 3, p.

STRECK, Danilo R.; REDIN, Euclides; ZITKOSKI, Jaime José (orgs). Dicionário Paulo Freire. Belo Horizonte: Autêntica, 2008. 